\title{
Semi-Elective Cervical Disc Replacements for Cervical Myelopathy: A Qualitative Study
}

\author{
Simon D Taylor- \\ Robinson (ID) \\ Guglielmo Trovato $\mathbb{D}^{2}$ \\ 'Department of Surgery and Cancer, \\ Imperial College London, London, UK; \\ ${ }^{2}$ Department of Medicine, University of \\ Catania, Catania, Italy
}

\begin{abstract}
Cervical disc prolapse can be accompanied by severe pain, numbness, paraesthesiae and muscle weakness. The choice lies between a conservative approach with physiotherapy and pain modulating drugs, such as gabapentin, or a more active surgical approach, ranging from nerve decompression through vertebral foraminotomy through to cervical disc replacement. We relate the experience of a medically qualified patient in having disc prolapse at three cervical levels and what it was like to experience a lonely and difficult post-surgical recovery. Despite this, the patient would still choose active surgical decompression over a non-interventional approach. The reasons for this are discussed from the patient perspective, of which there is little directly in the medical literature.
\end{abstract}

Keywords: chronic pain, neurosurgery, operative choices, cervical disc prolapse

\section{Introduction}

Cervical disc prolapse can be a very disabling experience for most patients who may have protracted time off work through chronic pain, inability to use the affected arm in activities of daily living, consequent muscle wasting and often, associated psychological and economic sequelae that accompany long-term illness. ${ }^{1}$

Therapeutic options are not supported by good evidence in meta-analyses, either for conservative treatment with physiotherapy and pain-modulating drugs or for active surgical options, such as cervical disc replacement. ${ }^{2,3}$

\section{Methodology}

We report the experience of a well-known medically qualified practitioner who spoke to the authors in a face-to-face interview about his experiences of 15 months off work following cervical disc prolapse. The interview with the patient was recorded digitally, after he provided written, informed consent. The recorded interview was then fully transcribed into a Microsoft Word ${ }^{\mathrm{TM}}$ (Microsoft, Redmond, Washington, USA) text document and the context organised into themes for thematic analysis by each of the two authors who acted independently. Inter-rater reliability was greater than $70 \%$, using Cronbach's alpha test.

\section{Description}

The patient was initially offered conservative management and suffered much physical and psychological distress in the process. As a medical academic, he had been used to travelling round the world with little thought for his own health, but this problem confined him at home with disabling pain. He felt that his experiences
Correspondence: Simon D Taylor-Robinson Department of Surgery and Cancer, Imperial College London, South Wharf Street, London, W2 !NY, UK

Email Str338333@gmail.com 
were typical of the ambivalent approach taken by the medical profession, rather than offering active surgical decompression earlier in the natural history of the complaint.

The patient was not quite sure when his symptoms started, but he gradually became aware that he had numbness in his thumb and fingers of his left hand. Weakness ensued and he found difficulty in activities of daily living, such as doing up buttons. He began to drop things, but only when radicular pain and paraesthesiae started, did he stop ignoring his symptoms. He reported: "The pain seemed like fireworks shooting down my left arm and there really was little relief'.

On a work trip to Abu Dhabi from his workplace in London, United Kingdom, his medical hosts perceived his pain and arranged an MRI of his neck and thoracic spine, amongst an array of tests. To his surprise, the radiology report indicated that he had slipped his C 5-6, C 6-7 and C 7-8 vertebral discs. A local medical expert explained that if one disc had herniated, neighbouring discs can rupture like opening a zipper. Given that the patient had travelled a lot, it was suggested that he had probably sustained the injury on wrestling with suitcases on an airport luggage carousel, perhaps on a previous visit to Mexico - the injury being a result of different shear forces moving in opposite directions.

He had been told in Abu Dhabi that operations to relieve the pressure on cervical nerves had mixed results and that he might be better having physiotherapy and being managed conservatively. ${ }^{1}$ This decision was confirmed by the neurologist in the United Kingdom to whom he was referred - weekly physiotherapy of the neck, shoulder and arm was arranged. Gabapentin was given for pain, but on interview he reported the following: "I never felt that it made any difference at any point which for an optimist, it was saying something". 2

While weekly physiotherapy sessions were designed to improve muscle strength and prevent sarcopenia, they did little to improve the pain, which coursed down his arm at the slightest provocation. He recalled at interview: "life was miserable, but I continued to soldier on at work".

It was on work trip to West Africa that he realised that quality of life was all important and that he could no longer tolerate the pain.

Every pothole in the African roads was felt - like starting up a firecracker in my arm. I knew that surgery was needed to put me out of my misery. I knew if I had been a limping horse, I would have been 'put down' out of kindness.

On return to the United Kingdom, he was eventually referred to one of the regional neurosurgery centres. The multidisciplinary team who assessed him not only included the surgeon, but a physiotherapist and a specialist nurse. The physiotherapist examined all his neurological deficits in detail and came up with a postsurgical recovery plan, while the specialist nurse gave him information on what to expect and what he might experience in the early days after an operation to relieve his trapped nerves. He reported: "It was a well-oiled machine and I received a surgical date for cervical nerve root decompression and disc replacements within the fortnight".

The day of the operation loomed; he recalled:

I was racked with pain and inconvenienced by weakness in my dominant hand. I could not write, undertaking clinical activity was difficult and I continued to be clumsy, dropping things with seeming alacrity.

He was told that an anterior approach would be made to remove the herniated discs and replace them with titanium carbide ones, which would last far longer than his life span. $^{3}$

On the video given to him as part of the patient information process, the artificial discs looked like oysters with a pearl inside - allowing both swivelling movements about the "pearl" and both backwards-forwards and side-to-side movements about the axes of the "oyster shell".

The pre-operative process was reported to be very slick, the anaesthetist was reassuring and the surgical team efficient. In the post-operative period, he realised that it was difficult to swallow and that he was somewhat hoarse (possibly from recurrent laryngeal nerve bruising, given the anterior approach which was used). While he was discharged within 24 hours, recovery was slower than he would have liked - he had to eat soft food for many weeks. He lost a lot of weight and found himself trapped at home, as he did not have the strength to open the heavy front door.

He recalled at interview:

It is these things in the intermediate recovery period that the surgical team do not realise, given that most people have recovered at the 3 month post-surgical check-up, although quietly undergoing weeks of hell in the intervening time from hospital discharge. However, I still had 
quite disturbing paraesthesiae and numbness in my thumb and fingers, although I found myself acting cheerily, so as not to seem difficult or ungrateful.

The subsequent months continued with physiotherapy, more gabapentin and eventually a brachial plexus block, performed by a radiologist who entered the room (as the patient recalled) and undertook the procedure without even introducing himself. The radiologist was remembered to have left as quickly as he arrived. The patient said "I felt like a bit of meat and very disconsolate". At interview, the patient discussed with us that kind words are all important and that he felt that in his experience, kindness was rarely encountered. He stated:

I was shocked at how many medics failed to distribute words of comfort in the rush to get on with the next case or whatever else might be exercising their minds. ${ }^{4}$

He went on to reflect: "I was sad to say that the procedure didn't work and I was just as afflicted as ever with pain still coursing down my arm venomously".

\section{Results}

Eventually, after much deliberation and countless scans, he was slated for a further operation, a full 8 months after the first. This time, large foraminotomies were made to release the still trapped nerves, using a posterior approach. ${ }^{5}$ While the classic teaching is that it is more difficult to recover from this type of operation than the anterior approach, the patient found himself back at work within 6 weeks and shortly afterwards, in Abu Dhabi once more. He reflected "I had come full circle and had learnt much about the resilience that our patients need in order to survive and eventually flourish".

\section{Lessons Learned}

It is now 10 years on from the initial problem - the patient reflects that he still has numbness in the thumb and index finger of his left hand, but he disclosed that the power has returned and the pain has gone. On reflection, he asserts that he would still have taken the surgical route if he had his time again. He pointed out that inaction and conservative treatment was associated with depression both from inactivity, an inability to carry out the activities of daily living and because of chronic unremitting pain.

He stated

There may be often unanticipated bumps in the postsurgical road, but at least that option did something active, unlike the conservative approach, which I felt lost me time and only brought me protracted pain. I feel that medical authorities who compare both approaches probably have not experienced the pain involved themselves.

\section{Conclusions}

Spinal surgery comprises a series of complicated and difficult procedures, which can only be undertaken by highly skilled specialists. Such surgery carries with it the potential of long-term neurological, vascular or bony complications, which vary according to the procedure and the spinal level being operated upon. ${ }^{6-8}$ All such procedures should be considered with caution, but if successful, spinal surgery can offer great relief to the patient, as we have detailed in our current study.

In this light, we believe that more should be written about the patient experience, given that meta-analyses are still stymied by lack of strong evidence on what approach to take - active surgical procedures or inactive medical supportive approaches. If quality of life is to be considered, then the surgical approach is to be recommended from the viewpoint of our patient. ${ }^{1}$

While we acknowledge that this study is limited by the sample size being from one patient, no other comparable information on patient preference or experience exists in the literature in this context and we therefore believe that the transcript of our conversations with the patient merit publication to stimulate further discussion.

\section{Statement of Human and Animal Rights}

All procedures undertaken in this study were in accordance with local research ethics committee protocols and with the 1975 Declaration of Helsinki on Human Rights.

\section{Ethical Approval}

The local Research Ethics Committee did not require ethical approval for the authors to speak to the patient, provided prior written, informed consent was obtained.

\section{Statement of Informed Consent}

Written informed consent was obtained from the patient for their anonymized information to be published in this article. The patient approved the final draft of the manuscript. 


\section{Acknowledgments}

We thank Professor Marsha Y. Morgan for reading the manuscript and making helpful comments on language, style and content. The authors are also grateful to Dr Mark McPhail for helpful advice and suggestions.

\section{Funding}

SDT-R is grateful to the United Kingdom National Institute for Healthcare Research at Imperial College London for infrastructure support and the Wellcome Trust Institutional Strategic Support Fund for funding (Grant number 105603/Z/1/Z).

\section{Disclosure}

The authors report no conflicts of interest.

\section{References}

1. Gebremariam L, Koes BW, Peul WC, Huisstede BM. Evaluation of treatment effectiveness for the herniated cervical disc: a systematic review. Spine. 2012;37:E109-E118. PMID: 21587105. doi:10.1097/ BRS.0b013e318221b5af

2. Dogu H, Ozdemir NG, Yilmaz H, Atci IB. Long-term follow-up results of surgically treated patients with foraminal and far lateral disc herniations. Br J Neurosurg. 2021:1-8. PMID: 33502266. doi:10.1080/02688697.2021.1874293
3. Othman YA, Verma R, Qureshi SA. Artificial disc replacement in spine surgery. Ann Transl Med. 2019;7(Suppl 5):S170. PMID: 31624736; PMCID: PMC6778281. doi:10.21037/atm.2019.08.26

4. Savulescu J, Foddy B, Rogers J. What should we say? J Med Ethics. 2006;32:7-12. PMID: 16373515; PMCID: PMC2563280. doi:10.1136/jme.2005.012781

5. Liu WJ, Hu L, Chou PH, Wang JW, Kan WS. Comparison of anterior cervical discectomy and fusion versus posterior cervical for aminotomy in the treatment of cervical radiculopathy: a systematic review. Orthop Surg. 2016;8:425-431. PMID: 28032703; PMCID: PMC6584082. doi:10.1111/os.12285

6. Porche K, Maciel CB, Lucke-Wold B, et al. Preoperative prediction of postoperative urinary retention in lumbar surgery: a comparison of regression to multilayer neural network. $J$ Neurosurg Spine. 2021:1-10. PMID: 34507288. doi:10.3171/2021.3.SPINE21189

7. Katsevman GA, Turner RC, Lucke-Wold BP, Sedney CL, Bhatia S. Osteopathia striata with cranial sclerosis (OSCS): review of the literature and case report demonstrating challenges of spinal fusion after trauma. Acta Neurochir. 2016;158:1115-1120. PMID: 27068044. doi:10.1007/s00701-016-2794-4

8. Bonasso PC, Lucke-Wold BP, d'Audiffret A, Pillai L. Primary endovascular repair of ilio-caval injury encountered during anterior exposure spine surgery: evolution of the paradigm. Ann Vasc Surg. 2017;43:316.e1-316.e8. PMID: 28479457; PMCID: PMC5560597. doi:10.1016/j.avsg.2017.03.192.
Patient Preference and Adherence

\section{Publish your work in this journal}

Patient Preference and Adherence is an international, peer-reviewed, open access journal that focusing on the growing importance of patient preference and adherence throughout the therapeutic continuum. Patient satisfaction, acceptability, quality of life, compliance, persistence and their role in developing new therapeutic modalities and compounds to optimize clinical outcomes for existing disease

\section{Dovepress}

states are major areas of interest for the journal. This journal has been accepted for indexing on PubMed Central. The manuscript management system is completely online and includes a very quick and fair peer-review system, which is all easy to use. Visit http:// www.dovepress.com/testimonials.php to read real quotes from published authors. 